\title{
A QUEBRA DO ESPELHO: SEXUALIDADE E IDENTIDADE EM HAMLET
}

\author{
LA QUEBRA DEL ESPEJO: SEXUALIDAD Y IDENTIDAD EN HAMLET
}

THE MIRROR BREAK: SEXUALITY AND IDENTITY IN HAMLET

\author{
Leny André PIMENTA ${ }^{1}$ \\ Maria Regina MOMESSO ${ }^{2}$ \\ Paulo Rennes Marçal RIBEIRO ${ }^{3}$
}

RESUMO: Este artigo propõe refletir sobre as questões da sexualidade e identidade em Hamlet. O corpus de análise é um recorte de três cenas do RPG digital "Mabinogi: Hamlet - 'To be, or not to be'. O suporte digital constitui-se de um hibridismo de linguagens e este provoca uma (re)configuração educacional, pois aciona no jogador digital e leitor habilidades e competências diferentes da mídia impressa. Sabe-se que a sexualidade tem sido problematizada, ao longo da história, por meio da literatura e das reflexões que se inscrevem em diferentes linguagens culturais, a partir das diversas práticas e discursos circulantes, em que se produzem possibilidades de subjetivação. Diante do exposto pretende-se ir ao encontro de inquietações que geram algumas questões: A literatura, inscrita em um suporte digital, favorece a "experiência de si" em relação ao cotidiano da sexualidade humana? O ódio do desejo é o que move a quebra do espelho para o reconhecimento de si? O aparato teórico-metodológico dessa reflexão assenta-se na perspectiva discursiva francesa e no viés da psicanálise lacaniana. Observa-se que o sujeito pode, por meio da literatura, ser levado a observar a si mesmo, analisar-se, decifrar-se, reconhecendo-se como um domínio de sua verdade, e nesse sentido a sua subjetividade constrói seu entendimento do que seja sexualidade ou ressalta os recalques dos desejos incompreendidos.

PALAVRAS-CHAVE: Sexualidade. Identidade. Discurso. Psicanálise.

RESUMEN: Este artículo propone reflexionar sobre las cuestiones de la sexualidad e identidad en Hamlet. El corpus de análisis es un recorte de tres escenas del RPG digital "Mabinogi: Hamlet - 'To be, or not to be'. El soporte digital se constituye de un hibridismo de lenguajes y éste provoca una (re) configuración educativa pues, acciona en el jugador digital y lector habilidades y competencias diferentes de los medios

\footnotetext{
${ }^{1}$ Universidade Estadual Paulista (UNESP), Araraquara - SP - Brasil. Doutoranda em Educação Escolar na UNESP/Araraquara. Diretora do Colégio Monteiro Lobato COC em Franca-SP. Pesquisadora do GESTELD (Grupo de Estudos em Educação, Sexualidade, Tecnologias, Linguagens e Discursos) vinculado à UNESP/CTI-FEB, Bauru, SP. E-mail: leny@ cocfranca.com.br.

${ }^{2}$ Universidade Estadual Paulista (UNESP), Araraquara - SP - Brasil. Docente do Programa de PósGraduação em Educação Sexual e do CTI-FEB. Coordenadora do grupo de pesquisa GESTELD, da FEBUNESP/Bauru. E.mail regina.momesso@feb.unesp.br.

${ }^{3}$ Universidade Estadual Paulista (UNESP), Araraquara - SP - Brasil. Docente dos Programas de PósGraduação em Educação Escolar e Educação Sexual. Livre-Docente em Sexologia e Educação Sexual. Coordenador do grupo de pesquisa NUSEX. E-mail: paulorennes@ fclar.unesp.br.
} 
impresos. Se sabe que la sexualidad ha sido problematizada, a lo largo de la historia, por medio de la literatura y de las reflexiones que se inscriben en diferentes lenguajes culturales, a partir de las diversas prácticas y discursos circulantes, en que se producen posibilidades de subjetivación. Ante la expuesta se pretende ir al encuentro de inquietudes que generan algunas cuestiones: ¿La literatura, inscrita en un soporte digital, favorece la "experiencia de sí" en relación al cotidiano de la sexualidad humana? ¿El odio del deseo es el que mueve la ruptura del espejo para el reconocimiento de sí? El aparato teórico-metodológico de esa reflexión se asienta en la perspectiva discursiva francesa y en el sesgo del psicoanálisis lacaniano. Se observa que el sujeto puede, por medio de la literatura, ser llevado a observarse a sí mismo, analizar, descifrarse, reconociéndose como un dominio de su verdad, y en ese sentido su subjetividad construye su entendimiento de lo que es Sea sexualidad o resalta los recalques de los deseos incomprendidos.

PALABRAS CLAVE: Sexualidad. Identidad. Discurso. Psicoanálisis.

ABSTRACT: This article it proposes to reflect on issues of sexuality and identity in Hamlet. The analysis corpus is a cutout of three scenes of digital RPG "Mabinogi: Hamlet - 'To be, or not to be'. The digital format is made up of a hybrid languages and this causes a (re) configuration educational therefore triggers the digital player and player different abilities and skills of print media. It is known that sexuality has been problematized, throughout history, through literature and reflections who subscribe to different cultural languages, from the various practices and discourses circulating in that produce subjectivity possibilities. Given the above it is intended to meet the concerns that generate some questions: Literature, enrolled in a digital format, favors the "experience of self" in relation to the daily life of human sexuality? The desire of hatred is what drives the mirror breaks for recognizing you? The theoretical-methodological apparatus of this reflection is based on French discursive perspective and bias of Lacanian psychoanalysis. It is observed that the subject can, through literature, be taken to observe yourself, be analyzed if decipher, recognizing as a domain of its truth, and accordingly its subjectivity builds your understanding of what is sexuality or highlights the repression of misunderstood desires.

KEYWORDS: Sexuality. Identity. Speech. Psychoanalysis.

"A palavra se faz carne, e a carne se faz palavra"

Donaldo Schüler

RIAEE - Revista Ibero-Americana de Estudos em Educação, Araraquara, v.12, n.4, p.2261-2273, out./dez. 2017. 


\section{Introdução}

Sabe-se que é por meio da linguagem que o sujeito aparece e se constitui em suas relações com o mundo e com o outro. Assim, nos propomos tomar a/da palavra como estância, reveladora do campo simbólico, universo discursivo por onde reverberam as mais diversas práticas discursivas, abrir vazios e pelas fendas emergir, escorregar, fluir outras tantas num constante entre/textecer de sentidos, a fim de provocar alguns clamores de interpretações. Para a Psicanálise e a Análise do Discurso, os sentidos são construídos de uma forma singular, na relação com o outro e com seu ambiente e, para isto, o sujeito tem que apropriar-se do campo da linguagem, principalmente pela fala (palavra) ${ }^{4}$.

Como o mito, a narrativa de histórias não surgiu como mero entretenimento dos grupos humanos mais antigos, mas como forma criativa de se explicarem os fenômenos da natureza, de se desenvolverem as potencialidades humanas e de capacitar o homem para intervir na realidade e transformá-la. O corpus, para este artigo, foi constituído a partir da análise de três cenas de um curta de animação intitulado "To be or not to be" de Hamlet no suporte digital YouTube: <http://www.youtube.com/watch?v=VjpNMJ4bXMA>. A reflexão sustenta-se na Análise do Discurso de "linha" francesa e na Psicanálise lacaniana, em que os postulados se ocupam da determinação histórica dos processos de significação, ao considerar que os sentidos são construídos de forma singular, na relação com o outro e em seu ambiente e, para isso, o sujeito tem que se apropriar do campo da linguagem.

\section{Identidade e Sexualidade: formações imaginárias e práticas discursivas}

Sabe-se que a sexualidade tem sido problematizada, ao longo da história, por meio da literatura e das reflexões que se inscrevem em diferentes linguagens culturais, a partir das diversas práticas e discursos circulantes, em que se produzem possibilidades de subjetivação. Em suas considerações, SILVA (1994, p. 42-43), afirma que Foucault vai estudar historicamente a sexualidade do ponto de vista da experiência; não estuda as ideias nem os comportamentos, diz o autor, “[...] mas, algo que pode ser separado analiticamente de ambos e que, ao mesmo tempo, os torna possíveis: a experiência de

${ }^{4}$ Lacan $(1979,275)$, nos alerta: “A palavra institui-se como tal na estrutura do mundo semântico que é o da linguagem. A palavra não tem nunca um único sentido, o termo, um único emprego. Toda palavra tem sempre um mais além, sustenta muitas funções, envolve muitos sentidos [...]”. 
si". É, em suma, a história da "subjetividade", se entendermos esta palavra como a maneira em que o sujeito faz a experiência de si mesmo em um jogo de verdade onde ela é em relação a si mesmo.

Em relação às representações das cenas de Hamlet, podemos fazer uma comparação com a análise discursiva de uma fotografia, em que Pimenta \& MonteSerrat (2013) salientam:

Podemos afirmar, então, que um objeto qualquer, uma fotografia, por exemplo, pode reclamar interpretação, causar questões e colocar o discurso de um sujeito em movimento na história e na língua. A significação está do lado do sujeito que o vê, relê, transvê, interpreta; e não do lado do objeto. E se descobrimos e construímos sentidos, há sempre algo que nos escapa, pontos de impossível que chamamos, a partir da perspectiva da psicanálise e da Análise do Discurso, de real (PIMENTA; MONTE-SERRAT, 2013, p. 93).

É justamente nesses "pontos de impossível” da língua, o lugar onde as palavras “faltam" e, por se ausentarem é que se propiciam brechas para produzir equívocos. Sabe-se que a língua é um sistema passível de falhas, e são nessas falhas, nesses furos, que os sentidos podem deslizar, ficando à deriva. Nesses furos, escoam a falta e as falhas. Eles são necessários, dada a incompletude do "dizer tudo"; assim, por meio desses furos, abre-se espaços para outros sentidos passarem.

Cabe esclarecer que as imagens (indivíduos, assuntos ou instituições) não surgem do acaso, considerando que o imaginário faz parte do funcionamento da linguagem e, para a Análise de Discurso, constitui uma das condições básicas para o processo de significação do discurso. Ressaltamos que esse mecanismo produz imagens dos sujeitos, assim como do objeto do discurso, dentro de uma conjuntura sóciohistórica, formadas pelo modo como ocorrem as relações sociais na história, e de como são organizadas por meio das relações de poder.

Dessa forma, Eagleton (2007) cita Althusser para concluir o conceito de ideologia:

[...] os homens de fato expressam, não a relação entre eles e suas condições de existência, mas o modo como eles vivenciam as relações entre eles e suas condições de existência: isso pressupõe tanto uma relação real quanto uma relação "imaginária", "vivida". [...] $\mathrm{Na}$ ideologia, a relação real é inevitavelmente investida da relação imaginária (EAGLETON, 2007, p. 21).

RIAEE - Revista Ibero-Americana de Estudos em Educação, Araraquara, v.12, n.4, p.2261-2273, out./dez. 2017. 
Portanto, considera-se a ideologia como uma representação das relações imaginárias dos indivíduos, pareadas às condições de existência. Complementamos com Pêcheux (2009), que ressalta como se constitui a formação discursiva:

[...] aquilo que, numa formação ideológica dada, isto é, a partir de uma posição dada, isto numa conjuntura dada, determinada pelo estado de luta de classes, determina o que pode e deve ser dito [...] (PÊCHEUX, 2009, p. 147).

Devemos lembrar que o sujeito discursivo é pensado como uma posição entre outras, considerando que a interpelação do indivíduo em sujeito, de seu discurso, se dá pelo processo de identificação com uma determinada formação discursiva que o afeta (a qual ele se constitui em sujeito). Justamente essa identificação é da ordem do imaginário do sujeito e apoia-se no interdiscurso, que mostra traços daquilo que o determina e é reinscrito no discurso do mesmo.

Dessa forma, percebe-se em Hamlet, complexas formações discursivas sócio/políticas, e etc., pois, era um príncipe, e como tal desejava herdar o reino da Dinamarca; assim, a partir das representações das personagens envolvidas na tragédia podem se conhecer os perfis socioculturais, psicológicos, psicanalíticos, delineados por estratégias de composição literária que refletem as formações discursivas das relações de saber e poder imbricadas no sujeito.

\section{Hamlet: sujeito de uma sexualidade na experiência de si}

O vídeo apresenta uma sequência de imagens do personagem Hamlet, em uma adaptação que o autor-diretor fez da obra shakespeariana de mesmo nome. Escolhemos para análise cenas em que a personagem Hamlet em frente ao espelho, onde o Grande Outro de Hamlet aparece através da dúvida, ao topar com a castração, que vai além da forma, da imagem (escópica) que lhe causa terror, angústia, porque revela algo de si. $\mathrm{Na}$ cena um, os elementos da linguagem verbal escrita "To die, to sleep. And by sleep end the heart-ache...” são equivalentes, análogos ao original de Shakespeare. 
Figura 1: Momentos de reflexão sobre morrer, dormir como solução para o término das angústias.

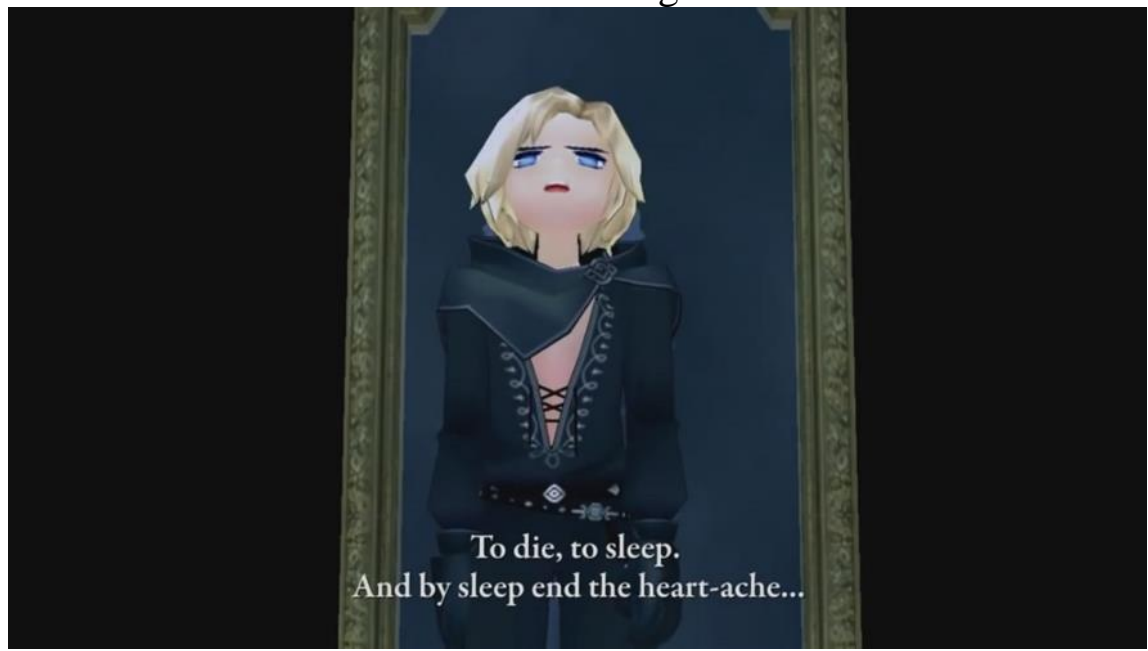

Fonte: <https://www.youtube.com/watch?v=VjpNMJ4bXMA>. Acesso em: 10 mar. 2017.

Em Hamlet vamos encontrar em "Morrer ou dormir. E com o sono acabar com as angústias" (fig. 1), o eco de seu próprio discurso verdadeiro, pois "o significante representa o sujeito para outro significante" numa impossibilidade de comunicação direta pessoa a pessoa como bem pontua Graña (2005, p.69). Percebe-se nesta cena o sofrimento psíquico capaz de produzir um enfraquecimento, um abalo narcísico, um colapso da identidade, abarcando a imagem de si e do Outro e, num delírio corporal representado (nesta cena) pelo enquadramento com predominância de tonalidade escura, olhar voltado para o alto como se esperasse algo do infinito para a resolução desse impasse, do qual ele, Hamlet, é acometido (causado em detrimento pela forte hesitação em seu impulso homicida, num mix de delírio com aparente melancolia), expressos por meio da linguagem imagética e sonora do vídeo (tonalidades escuras, sons graves), tudo isso somados ao trecho freudiano em "A Interpretação dos Sonhos" que vem bem a retratar esse sofrimento:

Hamlet é capaz de fazer qualquer coisa - salvo vingar-se do homem que eliminou seu pai e tomou o lugar deste junto a sua mãe, o homem que lhe mostra os desejos recalcados de sua própria infância realizados. Desse modo, o ódio que deveria impeli-lo à vingança é nele substituído por autorecriminações, por escrúpulos de consciência que o fazem lembrar que ele próprio, literalmente, não é melhor do que o pecador a quem deve punir. (FREUD, 1900 [1996, p. 281]).

Em Jones (1970) vamos encontrar em seu livro "Hamlet e o complexo de Édipo”, como um possível exercício do pensar analiticamente, as possíveis relações 
entre Édipo e Hamlet ${ }^{5}$, (influência da obra freudiana ${ }^{6}$ ), a saber: o envolvimento incestuoso da mãe (que lhe provoca repugnância) e, concomitantemente, o assassinato do pai (causa-lhe revolta, indignação), além do sentimento de decepção e ódio do tio homicida que se envolve com sua mãe em um enlaçamento amoroso. Dessa forma há um comprometimento e uma ruptura dos laços afetivos, em especial, entre Hamlet e Gertrudes (a mãe), pois, quando criança, Hamlet apresentava por ela um sentimento investido de teor erótico, efeito da exacerbação do apego da mãe por ele num misto de ternura/sensualidade, explicitado pelo autor (p.80).

Podemos deduzir as implicações das identificações imaginárias presentes em Hamlet que, segundo Lacan (2005[1962-1963]), apresenta-se em dois modos:

[...] Existe a identificação com $i(a),{ }^{7}$ a imagem especular, tal como esta nos é dada por ocasião da cena dentro da cena, e existe a identificação mais misteriosa, cujo enigma começa a ser desenvolvido aí, com o objeto do desejo tal, a, assim designado na articulação shakespeariana sem nenhuma ambiguidade, já que é justamente com o objeto do desejo que Hamlet é negligenciado, até um certo momento, e reintegrado na cena por meio da identificação (LACAN, 2005[19621963] p.46).

No momento do confronto angustiante de Hamlet (fig. 2) com o Outro marca o sujeito obsessivo pela emergência do objeto (a) que aparece na dialética do desejo, tão própria do obsessivo, que no dizer de Lacan (2005 [1962-1963]) é o momento da efusão, do "desvelamento traumático em que a angústia se revela tal como é, como aquilo que não se engana, momento em que o campo do Outro, por assim dizer, fendese e se abre para seu fundo. [...] trata-se, literalmente, de uma cessão", objeto cedível.

Assim, vamos encontrar em Hamlet um recobrimento imaginário do real na formação do $\mathrm{Eu}$, e, é por esse viés (da imago especular) que acontece a captura do sujeito no fascínio da identificação espacial e organiza seus fantasmas em uma matriz

\footnotetext{
${ }^{5}$ Salientamos que, aproximadamente existem mais de trinta referências de Freud a Hamlet, quase todas em relação ao contexto de elaboração do Complexo de Édipo.

${ }^{6}$ Em (vol. I) Obras completas, p. 307-308) apresenta Hamlet como "histérico", depois, Freud ao estudar a melancolia, descreve um funcionamento psíquico (o sentimento de culpa e a depreciação de si e do mundo) que pode ser exemplificado por meio da personagem Hamlet.

${ }^{7}$ Cabe aqui ressaltar que i(a) trata-se do ideal do Eu que equivale uma cristalização, uma operação que revela a matriz simbólica onde o Eu se precipita em uma forma (ideal), comporta o estatuto de uma fixação, proposta por Lacan a partir da leitura do artigo de Freud, "Sobre o narcisismo: uma introdução", citado por VANIER (2005, p. 49). Segundo CABAS (2009, p.118), o mesmo ideal que revela ser uma potência alienante demonstra ser, curiosamente e ao mesmo tempo, um dos suportes do Eu, da ideia-de-si e, por fim, da consciência.
} 
que vai da imagem despedaçada à figuração da sua totalidade, conforme pontua Cabas (2005, p.120).

Quais gestos de leitura poderiam se instaurar a partir das evidências, dos estranhos desejos, fabricados em Hamlet? O que o teria motivado? Seria o ciúme (edipiano) ao reconhecer que Gertrudes (sujeito mulher) é sedutora, portanto desejável? Ou seria um amor frustrado (narcisicamente) por ser pela segunda vez preterido?

Nesse sentido é ao Outro que Hamlet fala para apreender aquilo que se perdeu, e o Outro desliza silenciosamente sobre o formato das imagens que o compõe, ora reformando-o, ora deformando-o ora informando-o, e "quando o sujeito e o Outro se encontram produz um efeito de verdade, e a partir disto, certas coisas se tornam dizíveis, pensáveis, transmissíveis, utilizáveis”, como já citado anteriormente por Graña (2005, p.69). Compreende-se dessa forma que o Eu sempre será um movimento, “o esforço de ser e saber acerca de si e do mundo" (p.115). Do ponto de vista de Vanier (2005, p. 48) "o sujeito é, portanto, um lugar vazio, um furo no real, produzido pelo Simbólico, efeito do significante", e acrescenta, "ele aparece dividido: é por isso que Lacan o escreve \$. O Eu é o véu dessa divisão do sujeito".

Foucault (2014 [1971]) comenta em uma de suas aulas no Collège de France que:

Freud julgou que Édipo lhe falava do desejo, sendo que Édipo, por sua vez falava da verdade. É muito possível que o Édipo não defina a própria estrutura do desejo, mas o que Édipo narra é simplesmente a história de nossa verdade, e não o destino de nossos instintos. Somos submetidos a uma determinação edipiana, não no nível de nosso desejo, e sim no nível de nosso discurso verdadeiro. Ao ouvir o discurso verdadeiro do desejo, Freud julgou que estava ouvindo o desejo falar, sendo que era o eco de seu próprio discurso verdadeiro, sendo que era a forma à qual se subordinava seu discurso verdadeiro (2014 [1971], p.177-178). (grifo nosso).

Com a histórica aparição do (fantasma do) pai morto, aciona-se o campo do imaginário refletido, no campo do simbólico, por meio do desespero de Hamlet (fig. 2). Neste momento, Hamlet vira-se de costas para o espelho e abaixa, enquanto o Outro permanece em pé na mesma posição com os olhos voltados para baixo; é aí que acontece a ruptura e a vingança vem à tona.

RIAEE - Revista Ibero-Americana de Estudos em Educação, Araraquara, v.12, n.4, p.2261-2273, out./dez. 2017. 
Figura 2: Consumação desejada com ardor - Um simples golpe da espada poderia por fim a este tormento (tradução nossa)

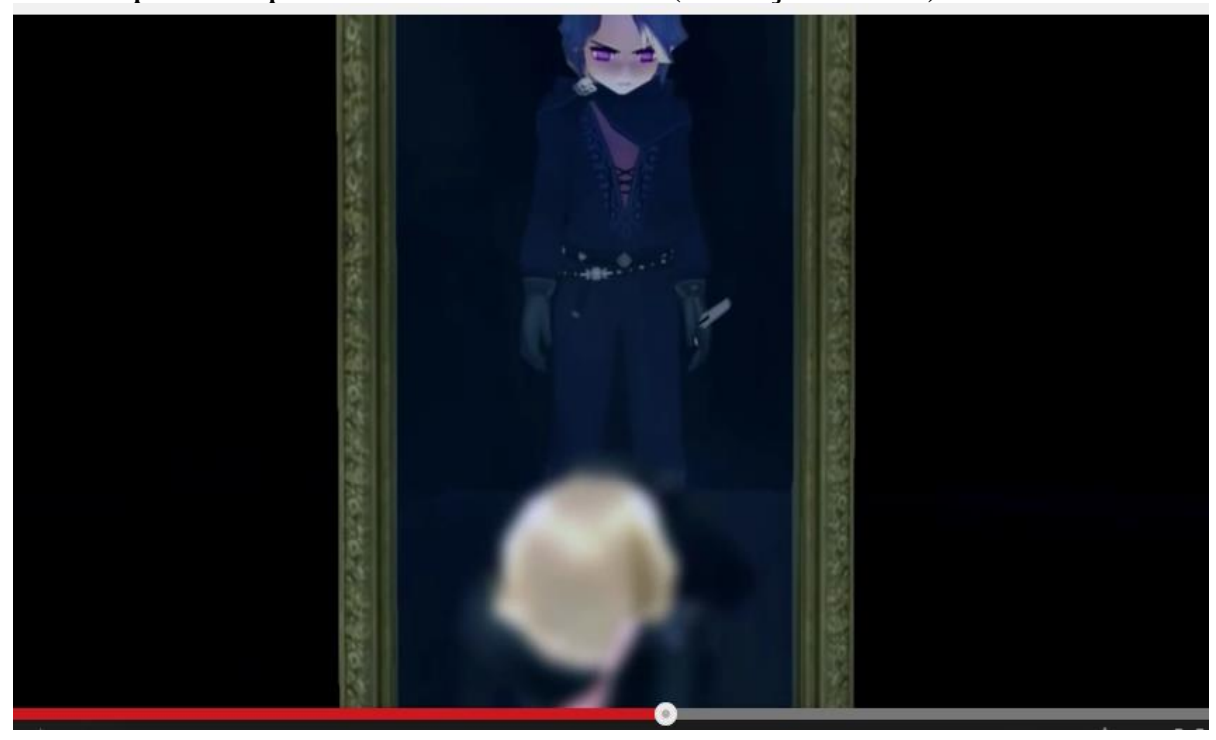

Fonte: <https://www.youtube.com/watch?v=VjpNMJ4bXMA>. Acesso em: 10 mar. 2017.

Figura 3: Hamlet - quebra o espelho (relação de ódio do Desejo)

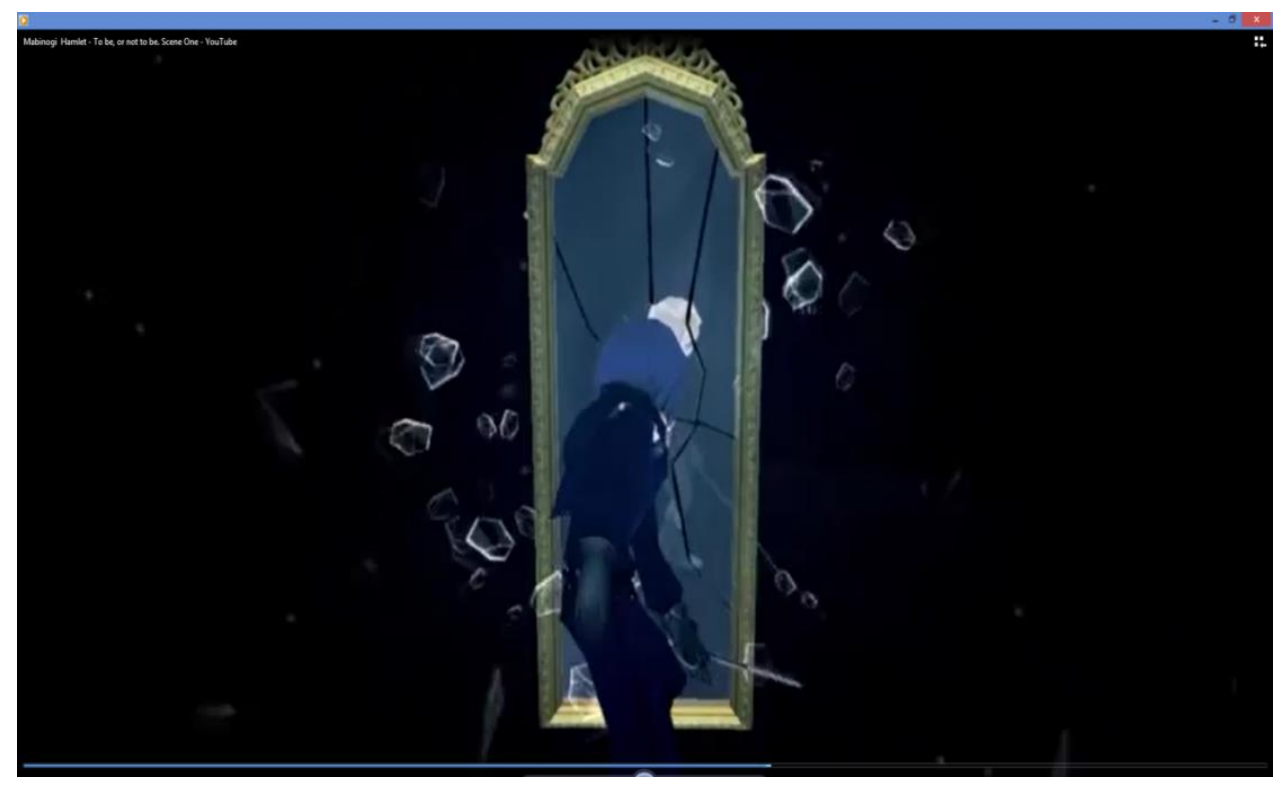

Fonte: <https://www.youtube.com/watch?v=VjpNMJ4bXMA>. Acesso em: 10 mar. 2017.

Há, neste momento, um atravessamento por meio do espelho (o imaginário é atravessado pelo simbólico) que mostra a clivagem (sujeito dividido), sob forma de recalque de uma possível culpa libidinosa, que se precipita dando vazão ao ódio do Desejo, culminando na quebra do espelho. Em relação ao ódio ao desejo, seguindo o 
pensamento lacaniano, Hamlet se encaixa em uma metáfora nomeada por Lacan $^{8}$ como metáfora paterna, citado por Vanier (2005, p.66) "a função paterna opera como uma metáfora, isto é, pela substituição de um significante por outro", embora Hamlet não tenha participado diretamente do assassinato do pai, ele está na fantasia de incesto e, consequentemente de parricídio, já que rememora a súplica deste Pai Morto, o fantasma (ghost), e a supor que a morte o requer. Assim sendo, ele coloca a morte no lugar do Desejo (Gozo), que mortifica o Outro, supondo-se sujeito em relação a essa morte, e dessa forma, assiste a sua vida do lugar de "morto", para não se dar conta da relação sintomática em existe em relação ao pai ${ }^{9}$. Pensar em Hamlet pelo viés foucaultiano é pensar em um sujeito de uma sexualidade que pode fazer uma experiência de si, reconhecendo-se como sujeito de desejo, conforme representa a fig. 02(a). Courtine (2013, p.57), ao considerar o corpo, o olhar e o discurso numa perspectiva arqueológica, comenta: trata-se, sobretudo de reconstruir, a partir de rastros de linguagens, os dispositivos dos quais os textos não são senão uma das formas de existência material. E, em igual medida, trata-se também de reconstruir práticas, de devolver vida aos gestos e carne aos corpos.

As análises das imagens apontam para uma intervenção do corpo, que vai aí marcar uma posição diferente do habitual, caberá ao simbólico por a nova aquisição em escritura e, ao imaginário, dar-lhe um sentido. Essa passagem do imaginário ao simbólico transforma a necessidade biológica na sexualidade humana: trata-se da identificação própria do segundo narcisismo, que permite ao sujeito situar a sua relação imaginária e libidinal. Dessa forma, o registro do imaginário assume o caráter de instância constitutiva da experiência perceptiva. Portanto, produzir a si próprio é um esforço contínuo, complexo, que se encontra sempre numa visão parcial de si mesmo, um voltar-se sobre si mesmo para dimensionar o que pode e deve fazer consigo mesmo.

${ }^{8}$ Lacan para expandir o conceito, retoma Roman Jakobson as noções de metáfora e metonímia e as identifica à condensação e ao deslocamento. Lacan, nos «Escritos», vai reconfigurar a teoria da Castração a partir da questão da metáfora paterna, porque nesta, o Desejo de Mãe (DM) e o Nome do Pai Simbólico, dariam conta das condições edípicas da Castração. No entanto, será somente em 1974/75, já próximo ao final da sua obra, no Seminário intitulado RSI, que foi inspirado em dois textos de Freud ( $\ll$ A Psicologia das Massas e Análise do Ego» e «O Ego e o Id») que Lacan vai configurar o Édipo como sinônimo de 2a identificação, (identificação ao traço unário do Nome do Pai) e a Castração na 3a identificação, porque só esta responde à questão Inconsciente: "o Desejo do homem é o Desejo do Outro".

${ }^{9}$ Como esclarecimento, representa o impasse entre o desejo de Hamlet por uma mãe sedutora e, ao mesmo tempo, a interdição de uma lei, figura paterna (representada pelo fantasma) que inviabilizam o acesso a este objeto super idealizado.

RIAEE - Revista Ibero-Americana de Estudos em Educação, Araraquara, v.12, n.4, p.2261-2273, out./dez. 2017. 


\section{Considerações finais}

Ao considerar Hamlet, da obra shakespeariana, como campo fértil para as múltiplas significações, a partir de campos teóricos da Análise de Discurso Francesa e da Psicanálise Freud-Lacaniana, nos possibilitou outros possíveis gestos de leitura, para interpretar a vida, o mundo e a si mesmo num movimento de ressignificação.

A priori, nosso intuito era o de apresentar as possibilidades de leituras mais significativas que colocasse o sujeito leitor no movimento dos sentidos a fim de provocar desconstruções na procura constante da diferença e da perda de si mesmo, reencontrar-se na singularidade como sujeito de uma sexualidade. Estabelecer interlocuções nas quais o Outro intervenha de modo reflexivo ancorado pela alteridade, que está em constante movimento de transformação pelo que nos é constitutivo: ou seja, o inacabamento do sujeito. E, também por uma exterioridade que se dilui com frequência. Enfim, buscou-se compreender as nuanças da sexualidade, a constituição da identidade a partir da identificação, das formações imaginárias e discursivas. Observouse que, assim como o "texto é tecido", como afirma Barthes (1973, p. 112), a vida também permite ser tecida, talvez ponto por ponto num movimento do alinhavo, algumas voltas na costura de rasgões na experiência de si, um constante trans/bordar de si. Empreende-se assim que o personagem de Hamlet faz um esforço no sentido de (re)descobrir-se e de (re)familiarizar-se com as formas de existência mais autênticas e mais libertadoras, portanto, há quebra do espelho.

\section{REFERÊNCIAS}

BARTHES, R. O Prazer do texto. Lisboa: Edições 70, 2001.

EAGLETON, T. A ideologia e suas vicissitudes no marxismo ocidental. In: ZIZEK, S.(Org.). Um mapa da ideologia. Rio de Janeiro: Contraponto, $3^{\mathrm{a}}$ reimpressão, 2007.

CABAS, A. G. O sujeito na psicanálise de Freud a Lacan: da questão do sujeito ao sujeito em questão. Rio de janeiro: Jorge Zahar Ed., 2009.

COURTINI, Jean-Jaques. Decifrar o corpo: pensar com Foucault. Petrópolis, RJ: Vozes, 2013.

GRAÑA, R. B. A carne e a escrita: um estudo psicanalítico sobre a criação literária. São Paulo: Casa do Psicólogo, 2005.

FOUCAULT, M. Aulas sobre a vontade de saber. Curso no Collège de France ( 19701971) seguido de: O saber de Édipo. São Paulo: Martins Fontes, 2014.

RIAEE - Revista Ibero-Americana de Estudos em Educação, Araraquara, v.12, n.4, p.2261-2273, out./dez. 2017. 
FREUD, S. A interpretação dos sonhos. In: FREUD, S. Edição comemorativa

Sigmund Freud (trad. Walderedo Ismael de Oliveira). Rio de Janeiro: Imago, 2001 (Trabalho original publicado em 1900).

JONES, E. Hamlet e o complexo de Édipo. (A. Cabral, trad.). Rio de Janeiro: Zahar, 1970.

LACAN, J.O Seminário (livro 10): a angústia. Rio de Janeiro: Jorge Zahar Ed., 2005.

LACAN, J. O seminário - Livro 1: Os escritos técnicos de Freud. Rio de Janeiro: Zahar, 1979.

LARROSA, J. Tecnologias do Eu e Educação. In: O sujeito da educação: estudos foucaultianos. $8^{\text {a }}$ ed. Petrópolis, RJ: Vozes, 2011.

PÊCHEUX. M. Semântica e discurso: uma crítica à afirmação do óbvio. Tradução de Eni Orlandi. 4 ed. Campinas: Editora da Unicamp, 2009.

PIMENTA, L.; MONTE-SERRAT, D. M. Instante decisivo como acontecimento no discurso fotográfico. Revista Intersecções, edição 9, ano 6, n. 1, maio/2013, p. 93.

SILVA, Tadeu Tomaz. (Org). O sujeito da educação: estudos foucaultianos. $8^{\mathrm{a}}$ ed. Petrópolis, RJ: Vozes, 2011.

VANIER, A. Lacan. Trad. Nícia A. Bonatti. São Paulo: Editora Estação Liberdade, 2005.

\section{Como citar este artigo:}

PIMENTA, Leny André.; MOMESSO, Maria Regina.; RIBEIRO, Paulo Rennes Marçal A quebra do espelho: sexualidade e identidade em Hamlet. Revista Ibero-Americana de Estudos em Educação, Araraquara, v. 12, n. 4, p. 2261-2272, out./dez. 2017. Disponível em: <http://dx.doi.org/10.21723/riaee.v12.n4.out./dez.2017.10772>. EISSN: 1982-5587.

Submetido em: 25/04/2017

Revisões requeridas: 17/06/2017

Aceito em: 06/07/2017 